\title{
Bottom-up control of whitefish populations in ultra-oligotrophic Lake Brienz
}

\section{Journal Article}

\section{Author(s):}

Müller, Rudolf; Breitenstein, M.; Bia, Mampsi M.; Rellstab, Christian; Kirchhofer, Arthur

Publication date:

2007-06

Permanent link:

https://doi.org/10.3929/ethz-b-000018795

\section{Rights / license:}

In Copyright - Non-Commercial Use Permitted

\section{Originally published in:}

Aquatic Sciences 69(2), https://doi.org/10.1007/s00027-007-0874-5 


\title{
Research Article
}

\section{Bottom-up control of whitefish populations in ultra-oligotrophic Lake Brienz}

\author{
Rudolf Müller ${ }^{1, *}$, Martina Breitenstein ${ }^{2}$, Mampasi Mbuenemo Bia ${ }^{1}$, Christian Rellstab ${ }^{3,4}$ and Arthur \\ Kirchhofer $^{2}$ \\ ${ }^{1}$ Eawag, Swiss Federal Institute of Aquatic Science and Technology, CH-6047 Kastanienbaum, Switzerland \\ ${ }^{2}$ WFN - Wasser Fisch Natur, Murtenstrasse 52, CH-3205 Gümmenen, Switzerland \\ ${ }^{3}$ Eawag, Swiss Federal Institute of Aquatic Science and Technology, CH-8600 Dübendorf, Switzerland \\ ${ }^{4}$ Institute of Integrative Biology, ETH Zürich, CH-8092 Zürich, Switzerland
}

Received: 14 July 2006; revised manuscript accepted: 12 January 2007

\begin{abstract}
Lake Brienz, an oligotrophic pre-alpine Swiss lake, went through a mesotrophic period between around 1960 and 1990. The lake is moderately turbid caused by fine suspended solids from glaciers. In 1999, yield of the economically important whitefish collapsed to about $10 \%$ of preceding years. Age and growth analysis of the two whitefish types examined - small and large type - revealed an almost complete halt of growth from 1999 until June 2000, paralleled by poor condition. Zooplankton data showed that cladocerans, the preferred food of whitefish, were rare from January 1999 until June 2000. In order to elucidate the trophic relationships between zooplankton and fish, the "Wisconsin Bioenergetics Model 3.0» was applied. The analysis showed that poor growth and condition of whitefish in 1999 and
\end{abstract}

2000 were caused by the scarcity of primary food organisms. The relatively small and slender fish could not be caught by legal gillnets, which resulted in poor fishing yield. Evidence is presented that cladoceran biomass governs food consumption by the fish («bottom-up effect»), while the effect of fish predation on cladocerans was found to be negligible, most likely also during the period of poor growth. Turbidity did not appear to significantly interfere with the feeding of whitefish. Growth, condition and commercial yield of whitefish partly increased again after 2000, but due to the very low productivity of Lake Brienz, fishing yield will remain low. Food chains in such oligotrophic systems are fragile. It is likely that a future collapse of the cladoceran population and, thus, the whitefish fishery will happen again.

Key words. Coregonids; fishing yield; food chain; bottom-up effects; bioenergetics model; oligotrophication.

\section{Introduction}

The production of fish biomass in natural waters is governed by primary production of the system, controlling zooplankton production, and mediated by the

* Corresponding author: phone: +41413492130 ; fax: +41 413492162 ; e-mail: rudolf.mueller@eawag.ch Published Online First: June 6, 2007 size and composition of the fish community. In lakes, the relationship between lake trophic state (in terms of phosphorus concentration), primary production and fish production is well established (Gerking, 1978; Downing et al., 1990; Downing and Plante, 1993; Kaiser et al., 1994). In general, eutrophic lakes support much higher fish production and fishing yield than oligotrophic lakes. Conversely, decreasing trophic state, a process referred to as oligotrophica- 


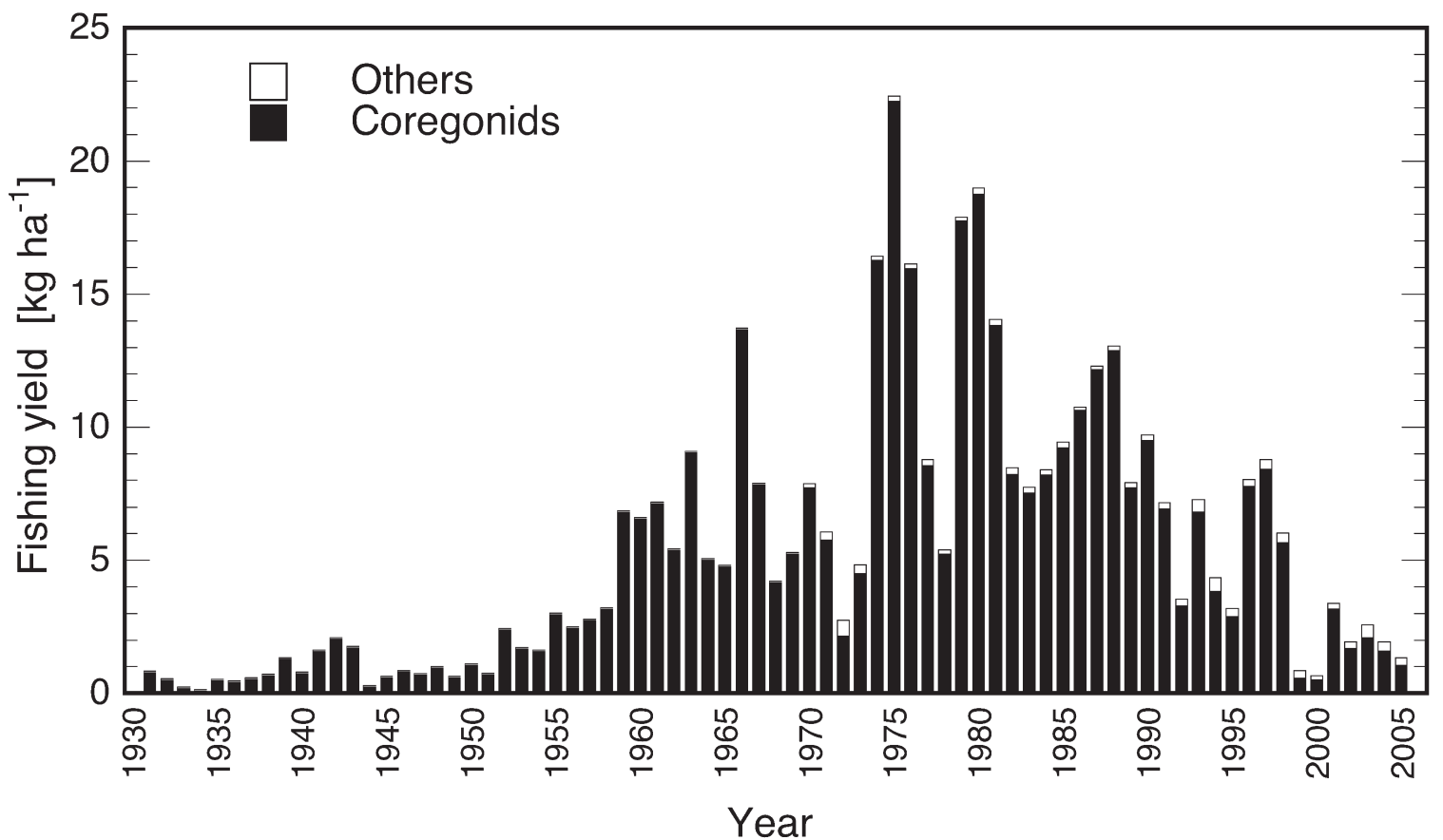

Figure 1. Fishing yield of the commercial fishery in Lake Brienz, years 1931-2005. Data obtained from the Fisheries Agency of the Canton Bern.

tion, leads to lower fish production and yield (Müller and Mbwenemo Bia, 1998; Eckmann and Rösch, 1998). While a decrease in total phosphorus concentration from very high $\left(>150 \mu \mathrm{g} \mathrm{L}^{-1}\right)$ to moderately high values $\left(30-60 \mu \mathrm{g} \mathrm{L}^{-1}\right)$ has rarely caused a significant drop in fishing yield (Müller and Stadelmann, 2004), fish production and yield tend to decrease quite rapidly at the lower end of the phosphorus scale, i.e. below $10-15 \mu \mathrm{g} \mathrm{L} \mathrm{L}^{-1}$ (Jeppesen et al., 2005; Rellstab et al., 2004). Thus, primary production seems to effect the food chain more profoundly at low nutrient levels. Furthermore, the interaction between fish as predators and zooplankton as prey complicates the situation in the course of oligotrophication, because zooplanktivorous fish may eliminate large grazers such as daphnids (Gaedke, 1999; Stich et al., 2005). Daphnids could eventually be replaced by smaller and less efficient grazers. This would further reduce fish production to a value well below the level expected based on primary production.

The major lakes of the Alpine region are typically deep, cold and oligotrophic. This was true until the onset of cultural eutrophication in the first half of the $20^{\text {th }}$ century. Between about 1960 and 1990, Swiss lakes passed through a temporary mesotrophic or even eutrophic phase. Some lakes have remained eutrophic (Liechti, 1994).

Two forms of European whitefish (coregonids) have dominated the fish fauna of Lake Brienz as reflected in the fisheries statistics (Fig. 1): the slowgrowing "Brienzlig" (hereafter referred to as "small type"), Coregonus albellus Fatio, and the fast-growing "Felchen" (hereafter referred to as "large type"), $C$. fatioi Kottelat (nomenclature according to Kottelat, 1997). Even though there are one or two more forms present in the lake (Kirchhofer, 1990; Bernatchez and Dodson, 1994; Douglas, 1998), these are not easily identifiable and at present not numerically important for the fishery. Fishing yield during the mesotrophic phase in 1970-1990 averaged $10.9 \mathrm{~kg} \mathrm{ha}^{-1}$ with a whitefish fraction of $98 \%$. In 1999 whitefish yield collapsed to $0.6 \mathrm{~kg} \mathrm{ha}^{-1}$ from $8.4 \mathrm{~kg} \mathrm{ha}^{-1}$ in 1997 and $5.7 \mathrm{~kg} \mathrm{ha}^{-1}$ in 1998 (Fig. 1). Yield was still low in 2000 but reached somewhat higher values in the following years. The collapse of the fishery prompted the authorities of the Canton Bern to initiate a comprehensive research project aimed at identifying the causes of the collapse, including all major factors acting on the ecosystem of Lake Brienz (Wüest and Zeh, 2007). Special attention was given to mechanisms underlying the collapse of the fishery and to the question if and how future collapses could be prevented.

In this work, major population parameters of the two most important whitefishes in Lake Brienz, such as growth, condition and year class strength, are presented. These data, together with data on zooplankton abundance in the lake, are then incorporated into a bioenergetics model for exploring the cause of 
the catch decline. Special attention was given to daphnids, the main food category in many whitefish populations (Rufli, 1979; Becker and Eckmann, 1992; Mookerji et al., 1998). Furthermore, a model of zooplankton-fish encounter probabilities was used to study the effect of food density and visibility on fish feeding and growth. The results of these models should help to formulate a prediction about future yield of the whitefish fishery in Lake Brienz, one of the main questions of the overall research project. The objective of this work was to test three hypotheses: 1 . Zooplankton concentration in 1999 and 2000 was the driving force behind the catch decline ("bottom-up effect"); 2. The whitefish population exerted topdown control of the zooplankton population in Lake Brienz during 1995-2003; and 3. Elevated turbidity had a strong negative effect on the feeding of the whitefish in 1999 and 2000. These hypotheses are tested at the level of populations ( $\mathrm{H} 1$ and $\mathrm{H} 2)$ and individuals $(\mathrm{H} 2$ and $\mathrm{H} 3)$.

\section{Materials and methods}

Lake Brienz, the uppermost large natural lake in the River Rhine catchment in Switzerland, reached a maximum of about $20 \mu \mathrm{g} \mathrm{L} \mathrm{L}^{-1}$ total phosphorus (TP) during 1980-1984. By the year 2000, TP and soluble reactive phosphorus (SRP) had decreased to about 7 and $1 \mu \mathrm{g} \mathrm{L} \mathrm{L}^{-1}$, respectively, due to effective water protection measures (Müller et al., 2007). Today, most TP is in a biologically inactive mineral form. The lake (surface area $29.8 \mathrm{~km}^{2}$, maximum depth $260 \mathrm{~m}$ ) receives considerable amounts of finely divided solids from glaciers that affect visibility and light penetration in the lake (Jaun et al., 2007). Data on primary production are scarce and can, for most of the time considered here, only be inferred from SRP values (Müller et al., 2007). In 1987 primary production was $100 \mathrm{~g} \mathrm{C} \mathrm{m}^{-2} \mathrm{a}^{-1}$ (Kirchhofer, 1990), whereas in 2004 it was $66 \mathrm{~g} \mathrm{C} \mathrm{m}^{-2} \mathrm{a}^{-1}$ (Finger et al., 2007). Maximum biomass of daphnids and total zooplankton decreased from 32.7-38.6 and 47.4-50.2 $\mathrm{g} \mathrm{m}^{-2}$ wet weight (range) in $1995-1996$ to $6.8-16.7$ and $23.6-26.6 \mathrm{~g}$ $\mathrm{m}^{-2}$ in 2001-2004, respectively. For detailed characteristics of Lake Brienz see Wüest and Zeh (2007).

Data and scale samples of Lake Brienz whitefish were obtained from the Fisheries Agency of the Canton Bern. The agency has been conducting a monitoring programme since 1984 by monthly sampling 25 whitefish from commercial gillnet catches (Kirchhofer, 1995; Kirchhofer et al., 2005). The fish sampled are measured and weighed, sexed, gillrakers counted for species identification, and scale samples taken for age and growth determination. The prime objective of the monitoring programme is to properly manage the whitefish populations, particularly for setting the legal mesh size of gillnets. Bar mesh size of the gillnets used in the commercial fishery until 1992 was $35-40 \mathrm{~mm}$ for bottom set nets used in winter, and $38 \mathrm{~mm}$ for floating nets used in spring, summer and autumn. In 1993, to counteract decreasing yields due to slower growth of whitefish, the legal mesh size was lowered to $30 \mathrm{~mm}$ for bottom set nets and to $35 \mathrm{~mm}$ for floating nets. From 1996, the legal mesh size of floating gillnets was $30 \mathrm{~mm}$ (Table 1). In 2004, small type whitefish were specifically caught with $20 \mathrm{~mm}$ nets on an experimental basis only.

The data used for this study comprised 5909 fish from years 1984-2004, including 347 fish from special catches in 1999, 2000 and 2001 with small-meshed nets (10-20 mm bar mesh). Scale age readings of all fish were verified, and a sub-sample of 1790 scales (49-364 per year) was measured for growth calculations. Growth was back-calculated using a binomial regression of total scale radius versus total length. Because back-calculated lengths showed bimodal length distributions at age 2 and older, all fish were assigned to either small type or large type whitefish by applying a cohort-specific threshold value for length-at-age (Müller, 2003). Condition was expressed by Fulton's condition factor $\mathrm{K}[-]$ as

$$
\begin{aligned}
& \mathrm{K}=\mathrm{W} 10^{5} \mathrm{~L}^{-3} \text { where } \mathrm{W}=\text { fish weight }[\mathrm{g}] \\
& \mathrm{L}=\text { total length }[\mathrm{mm}] .
\end{aligned}
$$

Table 1. Size and composition by type of whitefish catch samples from the monitoring programme, years 1984-2004, and sampling mesh size (bar length). Only samples from nets of legal mesh size, with the exception of 2004 when small-type whitefish were specifically sampled with $20 \mathrm{~mm}$ nets.

\begin{tabular}{lcccl}
\hline Year & $\begin{array}{l}\text { Sample size } \\
\text { (no. of individuals) }\end{array}$ & Large type \% & Small type \% & $\begin{array}{l}\text { Mesh size } \\
(\mathrm{mm})\end{array}$ \\
\hline 1984 & 267 & 92.5 & 7.5 & $35,38,40$ \\
1985 & 272 & 79.0 & 21.0 & $35,38,40$ \\
1986 & 274 & 24.5 & 75.5 & $35,38,40$ \\
1987 & 275 & 26.5 & 73.5 & $35,38,40$ \\
1988 & 262 & 24.4 & 75.6 & 35,38 \\
1989 & 274 & 31.8 & 68.2 & 35,38 \\
1990 & 275 & 59.3 & 40.7 & 35,38 \\
1991 & 275 & 54.5 & 45.5 & $35,38,40$ \\
1992 & 260 & 50.4 & 49.6 & 35,38 \\
1993 & 275 & 60.7 & 39.3 & $30,35,38$ \\
1994 & 275 & 59.3 & 40.7 & $30,35,38$ \\
1995 & 264 & 53.4 & 46.6 & 30,35 \\
1996 & 275 & 81.5 & 18.5 & 30,38 \\
1997 & 275 & 48.4 & 51.6 & $30,35,38$ \\
1998 & 274 & 54.7 & 45.3 & $30,35,38$ \\
1999 & 155 & 46.5 & 53.5 & 30,40 \\
2000 & 140 & 84.3 & 15.7 & 30 \\
2001 & 274 & 100.0 & 0.0 & 30 \\
2002 & 263 & 97.3 & 2.7 & 30 \\
2003 & 200 & 98.0 & 2.0 & 30 \\
2004 & 275 & 49.8 & 50.2 & 20,30 \\
\hline & & & & \\
\hline
\end{tabular}


The size of individual year classes was calculated in a worksheet application by virtual population analysis VPA (Ricker, 1975; Megrey, 1989, Haddon, 2001) and by adding an annual $20 \%$ natural mortality rate (Eckmann et al., 2002) for age classes two to eight. For calculating cohort size, the weight of the annual catch was assigned to small and large type whitefish according to the proportion and the mean weight in the monitoring samples. Changes in catch intensity were not included.

Trophic relationships between whitefish and zooplankton were assessed using the $«$ Wisconsin Bioenergetics Model 3.0» (Hanson et al., 1997). This model is based on an energy balance equation, including consumption, total metabolism, waste losses and growth:

Consumption $\mathrm{C}=($ respiration + active metabolism + specific dynamic action $)+($ egestion + excretion $)+$ (somatic growth + gonad production).

Using observed values of population structure and estimated population size from VPA and individual growth per year and year class for small type and large type whitefish separately, the model calculates the amount of energy consumed by the fish on a daily basis as specific consumption rates in $\mathrm{J} \mathrm{g}^{-1}$ of fish. Energy is then converted into biomass of food organisms consumed, i.e. zooplankton here. Estimates of physiological parameters for whitefish metabolism (weightdependent values for swimming speed, respiration, egestion and excretion) were taken from the «generalized coregonid model» by Rudstam et al. (1994; cit. in Hanson et al., 1997) in accordance with the procedure by Eckmann et al. (2002).

Consumption $\mathrm{C}\left[\mathrm{g} \mathrm{g} \mathrm{g}^{-1} \mathrm{~d}^{-1}\right]$ was adjusted to the annual variation in water temperature and to fish weight by

$\mathrm{C}=\mathrm{C}_{\max } \mathrm{p} \mathrm{f}(\mathrm{T})$ where

$\mathrm{C}_{\max }=$ maximum consumption rate, $\mathrm{p}=$ scaling factor [-] of $\mathrm{C}_{\max }(0<\mathrm{p}<1)$ accounting for ecological constraints on the maximum feeding rate, $f(T)=$ temperature dependence function [-] describing weight dependence at optimum and maximum temperature values, and

$\mathrm{C}_{\max }=\mathrm{CA} \mathrm{W}^{\mathrm{CB}}$ where

$\mathrm{W}=$ fish weight $[\mathrm{g}], \mathrm{CA}$ and $\mathrm{CB}=$ parameters of weight dependence function at optimum water temperature (Hanson et al., 1997).

The scaling factor $\mathrm{p}$ is calculated to adjust the estimated growth based on physiological parameters to the observed growth for each year class and year of study; $p$ varied between 0.15 and 0.34 for large type whitefish and between 0.12 and 0.22 for small type whitefish. Water temperatures were taken from the $0-$ $30 \mathrm{~m}$ depth range in temperature profiles measured monthly by the Laboratory for Water and Soil Protection of the Canton Bern (GBL) from 19942004 , and $f(T)$ is then calculated with temperature dependence values for warm-water species from Kitchell et al. (1977; cited in Hanson et al., 1997). Energy content of whitefish $\left(13,060 \mathrm{~J} \mathrm{~g}^{-1}\right)$, daphnids and copepods $\left(2513 \mathrm{~J} \mathrm{~g}^{-1}\right)$, and Bythothrephes and Leptodora $\left(949 \mathrm{~J} \mathrm{~g}^{-1}\right)$ were taken from Eckmann et al. (2002). Detailed stomach data for Lake Brienz whitefish (large type only) were from Maurer and Guthruf (2005). Energy losses due to reproduction were not included in the model.

The following population parameters were used in the bioenergetics model: cohort size at the start of the year, estimated fishing mortality according to catch statistics per month (only commercial catch), estimated average natural mortality per day, and mean individual weight of cohorts at the start and the end of the year. Specific consumption rates by small type and large type whitefish were first calculated as $g$ of zooplankton per $\mathrm{g}$ of fish $\mathrm{d}^{-1}$. These were then integrated to determine the total weight of zooplankton consumed by the whitefish population per day and summed to consumption per year. Growth, condition and consumption were compared with integrated zooplankton composition and biomass over the whole lake (data from Rellstab et al., 2007) to test hypothesis 1 about the «bottom-up effect» of catch decline. In periods with no daphnids in zooplankton samples, a density of 43 Daphnia $\mathrm{m}^{-2}$ (i.e. just below the detection level according to Rellstab et al., 2007) was assumed. Furthermore, Daphnia standing crop was related to total consumption by the whitefish population with a linear regression analysis in order to test hypothesis 2 about «top-down control» of the Daphnia population. A positive correlation between Daphnia standing crop and total daphnid consumption by the whitefish population would indicate a «bottom-up effect», whereas a negative correlation would indicate a «top-down effect».

Whitefish forage by vision and by snatching individual food items while cruising the lake. Therefore, Daphnia can only serve as food to whitefish if they are seen and if they are available in sufficiently high densities. To study these relations between Daphnia and individual whitefish, encounter probabilities were calculated by applying the model of visual range in fish by Aksnes and Giske (1993) and Aksnes and Utne (1997). Maximum encounter rate $\mathrm{E}$ in terms of daphnids s ${ }^{-1}$ was calculated as 


$$
\mathrm{E}=\pi(\mathrm{r} \sin \Theta)^{2} \mathrm{vN}\left[\mathrm{s}^{-1}\right]
$$

where $r \sin \Theta=$ «funnel searched» with $r=$ radius [m] and $\Theta=$ half angle of vision inside which the prey is seen and attacked, $\mathrm{v}=$ swimming speed $\left[\mathrm{m} \mathrm{s}^{-1}\right], \mathrm{N}=$ prey density (adult daphnids only) $\left[\mathrm{m}^{-3}\right]$.

The resulting maximum consumption rate $f\left[\mathrm{~s}^{-1}\right]$, which gives the number of prey $\mathrm{s}^{-1}$ and allows for handling time $\mathrm{h}$ [s] for capture and swallowing, is

$f=\frac{h^{-1} N}{\left(h \pi(r \sin \Theta)^{2} v\right)^{-1}+N}\left[\mathrm{~s}^{-1}\right]$

We used the following parameters:

$\mathrm{r}=0.05$ and $0.1 \mathrm{~m}$ for $1-2 \mathrm{~mm}$ size Daphnia (Link, 1996; Vinyard and O'Brien, 1976).

$\Theta=112.5^{\circ}$, as found in the laboratory for Coregonus artedi (Link, 1996, 1998).

$\mathrm{v}=0.3 \mathrm{~m} \mathrm{~s}^{-1}$, corresponding to an average cruising speed of 1-2 body lengths $\mathrm{s}^{-1}$ for large type and small type whitefish, which seems realistic as Jobling (1995) postulates $1-3$ body lengths as usual optimum swimming speed, and Büttiker (1975) estimated the cruising speed of whitefish in Lake Thun at $0.21-0.41 \mathrm{~m} \mathrm{~s}^{-1}$ by echo-sounding.

$\mathrm{h}=1 \mathrm{~s}$ for handling and swallowing 1 Daphnia (Mittelbach, 1981),

$\mathrm{N}=$ observed adult Daphnia density $\left[\mathrm{m}^{-3}\right]$ (Rellstab et al., 2007).

The effect of increased turbidity on the feeding of whitefish was investigated by assuming that the «visual range» $\mathrm{R}[\mathrm{m}]$ of the fish is shortened by reduced light transmission and light intensity, thus reducing the activity radius $r$ (= «funnel searched») and finally the feeding rate $\mathrm{f}$. The visual range $\mathrm{R}$ related to a target object can be expressed as a function of light, depth, target characteristics and an eye-inherent parameter (Aksnes and Giske, 1993; Aksnes and Utne, 1997):

$$
R^{2} e^{(c R+K z)}=\rho E_{0}\left|C_{0}\right| \pi \beta^{2} \Delta S_{e}^{-1}\left[\mathrm{~m}^{2}\right]
$$

$\mathrm{c}=$ beam attenuation coefficient $\left[\mathrm{m}^{-1}\right]$,

$\mathrm{K}=$ vertical attenuation coefficient $\left[\mathrm{m}^{-1}\right]$,

$\mathrm{z}=\operatorname{depth}[\mathrm{m}]$,

$\rho=$ irradiance loss at air-water surface $(0.5$ according to Aksnes and Giske, 1993),

$\mathrm{E}_{0}=$ irradiance at water surface $\left[\mu \mathrm{E} \mathrm{m}^{-2} \mathrm{~s}^{-1}\right]$,

$\mathrm{C}_{0}=$ inherent contrast of target $(0.5$ according to Aksnes and Giske, 1993); changes in contrast due to changing turbidity were not considered,

$\beta=$ target radius $(0.002 \mathrm{~m})$,
$\Delta \mathrm{S}_{\mathrm{e}}=$ sensitivity threshold of eye for detection of changes in irradiance $\left(1 \times 10^{-7} \mu \mathrm{E} \mathrm{m}\right)^{-2} \mathrm{~s}^{-1}$ according to Aksnes and Giske, 1993).

$\mathrm{R}$ has to be solved by iteration. At large depths, however, where $\mathrm{cR}<0.02(\mathrm{cR}+\mathrm{Kz}), \mathrm{cR}$ can be neglected and $\mathrm{R}$ can be solved as follows (Aksnes and Giske, 1993):

$R=\left(\rho E_{0} \exp (-K z)\left|C_{0}\right| \pi \beta^{2} \Delta S_{e}^{-1}\right)^{1 / 2}[\mathrm{~m}]$

The relation between visual range $\mathrm{R}$, radius $\mathrm{r}$ of the funnel searched and encounter rate $\mathrm{E}$ of fish with Daphnia can be expressed such that $\mathrm{E}$ is a function of $\mathrm{r}$ when $\mathrm{R}>\mathrm{r}$, and $\mathrm{E}$ is a function of $\mathrm{R}$ when $\mathrm{R}<\mathrm{r}$. With these relationships, the effect of increased turbidity on the feeding rate of whitefish can be modelled under various conditions. Light intensity, transmission values and attenuation coefficients at depths $0-50 \mathrm{~m}$ in Lake Brienz from in situ measurements between January 1999 and December 2004 according to Jaun et al. (2007) were used to assess the effects of changes in light distribution on whitefish feeding and to test hypothesis 3. In addition, simulations of vertical distribution of suspended particles in the lake with and without upstream dams (Finger et al., 2006) were used to study the influence of hydropower on whitefish feeding as suspected by fishermen.

In order to assess sustainable fishing yield at actual food concentrations, the carrying capacity for the whitefish population of the whole lake was estimated assuming that $1.5 \%$ of the standing crop of adult Daphnia is consumed per day. Rellstab et al. (2007) found that the mean net growth rate (which already includes a mean predation rate) of the Daphnia population varied between 1.5 and $9.4 \%$ in spring 1986-2005. We therefore assume that the Daphnia population is not endangered as long as consumption by whitefish remains below $1.5 \%$ of the standing crop per day. Carrying capacity is then compared to total consumption resulting from specific consumption rates as calculated with the bioenergetics model, and from feeding rates as calculated with the encounter model.

\section{Results}

The two coregonids made up highly varying proportions in the commercial catch, with large type whitefish contributing between $24.4 \%$ and $100 \%$ each year (Table 1). The share of large type coregonids in the samples from the special catches with small-meshed nets was $58.5 \%$ in $1999(\mathrm{n}=41), 34.6 \%$ in $2000(\mathrm{n}=$ $197)$ and $9.0 \%$ in $2001(\mathrm{n}=100)$. In spite of the substantial reduction in legal mesh size between 1984 

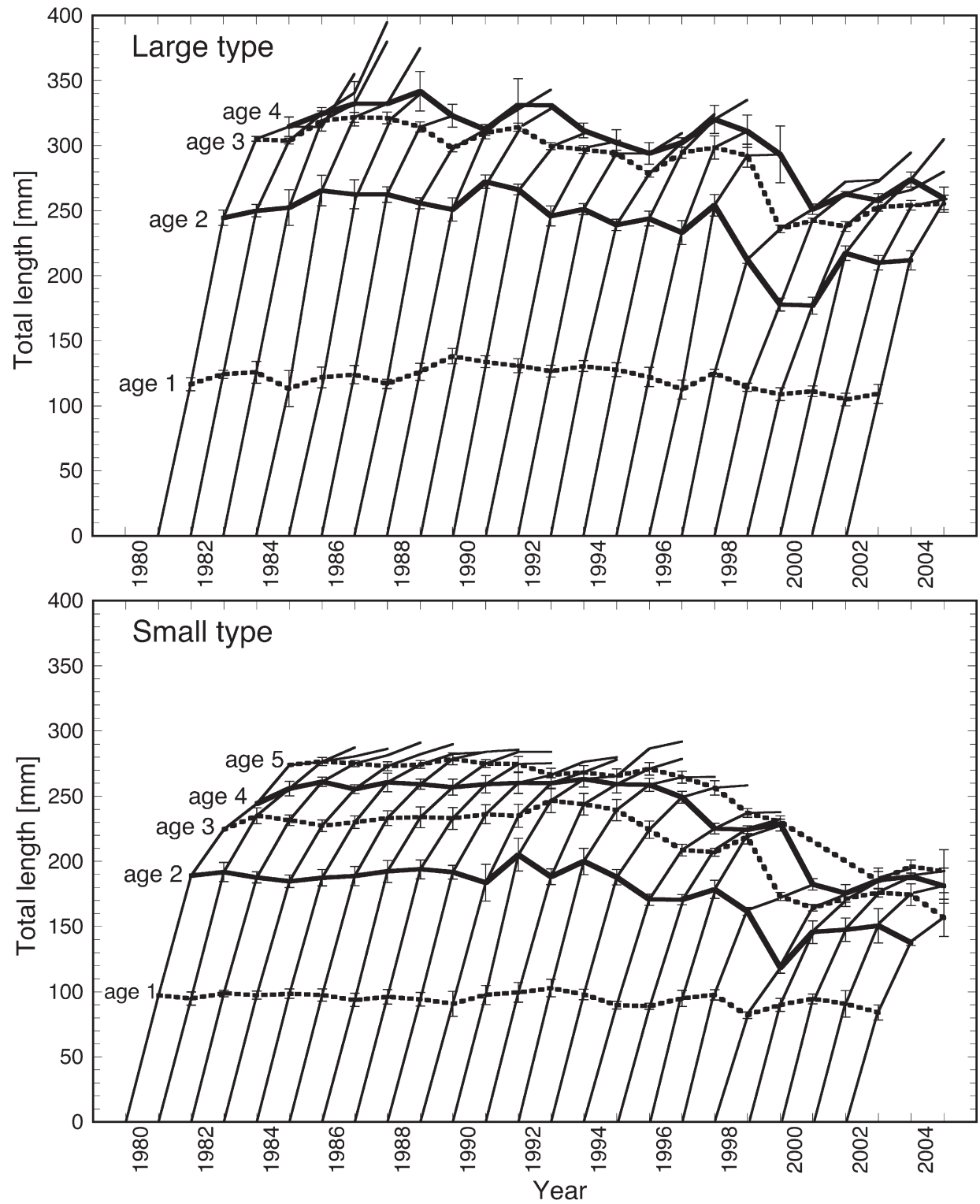

Figure 2 Growth of Lake Brienz coregonids, by cohort and age group. Top: Large type whitefish "Felchen" (n=2294), bottom: Small type whitefish "Brienzlig" $(\mathrm{n}=1675)$. Error bars indicate $95 \%$ confidence interval of the mean.

and 2004 (Table 1), average age-at-capture of large type whitefish increased from 2.61 years $(\mathrm{SD}=0.50, \mathrm{n}$ $=247)$ in 1984 to 3.16 years $(\mathrm{SD}=0.90, \mathrm{n}=137 ; \mathrm{t}=$ 6.547, $\mathrm{P}<0.001)$ in 2004. Likewise, mean age-atcapture of small type whitefish in the legal-size gillnets increased from 3.17 years $(\mathrm{SD}=1.54, \mathrm{n}=18)$ in 1984 to 3.93 years $(\mathrm{SD}=1.00, \mathrm{n}=89 ; \mathrm{t}=1.963$, n.s. $)$ in 2004 .

Growth in length of both types of coregonids was fair until the early $1990 \mathrm{~s}$ (Fig. 2). In the course of the $1990 \mathrm{~s}$, growth slowly decreased. In 1999 and 2000, growth of both types strongly decreased in fish older than one year. After 2000, growth increased again but did not attain former values. In large type whitefish, length of year classes $2000-2002$ at age 3 was $87 \%$ of that of year classes 1990-1995. In small type whitefish, however, growth remained poor with fish barely reaching $20 \mathrm{~cm}$ in length even at age 5 , as compared to $27-28 \mathrm{~cm}$ before 1995 .

Growth of Lake Brienz whitefish in terms of annual length increments was compared with the abundance of adult daphnids. There was a significant positive linear relationship between growth of small type whitefish and daphnid biomass in Lake Brienz during the main growing season from May to September, with the exception of fish in their first year. For large type whitefish, the relationship was also positive but not significant, with the exception of fish in their fourth year (Fig. 3, Table 2). Also, data for 
Table 2. Regression parameters of Figure 3: $d L / d t=a+b$ B. $P$ indicates significance of the slope $b$.

\begin{tabular}{|c|c|c|c|c|c|}
\hline Growth type & $\mathrm{a}[\mathrm{mm}]$ & $\mathrm{b}[\mathrm{mm}]$ & $r^{2}$ & $\mathrm{n}$ & $\mathrm{P}$ \\
\hline Large year 1 & 108.7 & 0.940 & 0.22 & 8 & 0.24 \\
\hline Large year 2 & 79.9 & 4.264 & 0.35 & 9 & 0.09 \\
\hline Large year 3 & 41.8 & 1.156 & 0.08 & 10 & 0.43 \\
\hline Large year 4 & 7.9 & 1.848 & 0.55 & 9 & 0.02 \\
\hline Small year 1 & 88.1 & 0.436 & 0.08 & 8 & 0.50 \\
\hline Small year 2 & 42.8 & 4.291 & 0.81 & 9 & 0.001 \\
\hline Small year 3 & 21.4 & 2.058 & 0.40 & 10 & 0.049 \\
\hline Small year 4 & 7.6 & 1.482 & 0.84 & 10 & 0.0002 \\
\hline
\end{tabular}

large type whitefish showed more variation than data for small type whitefish.
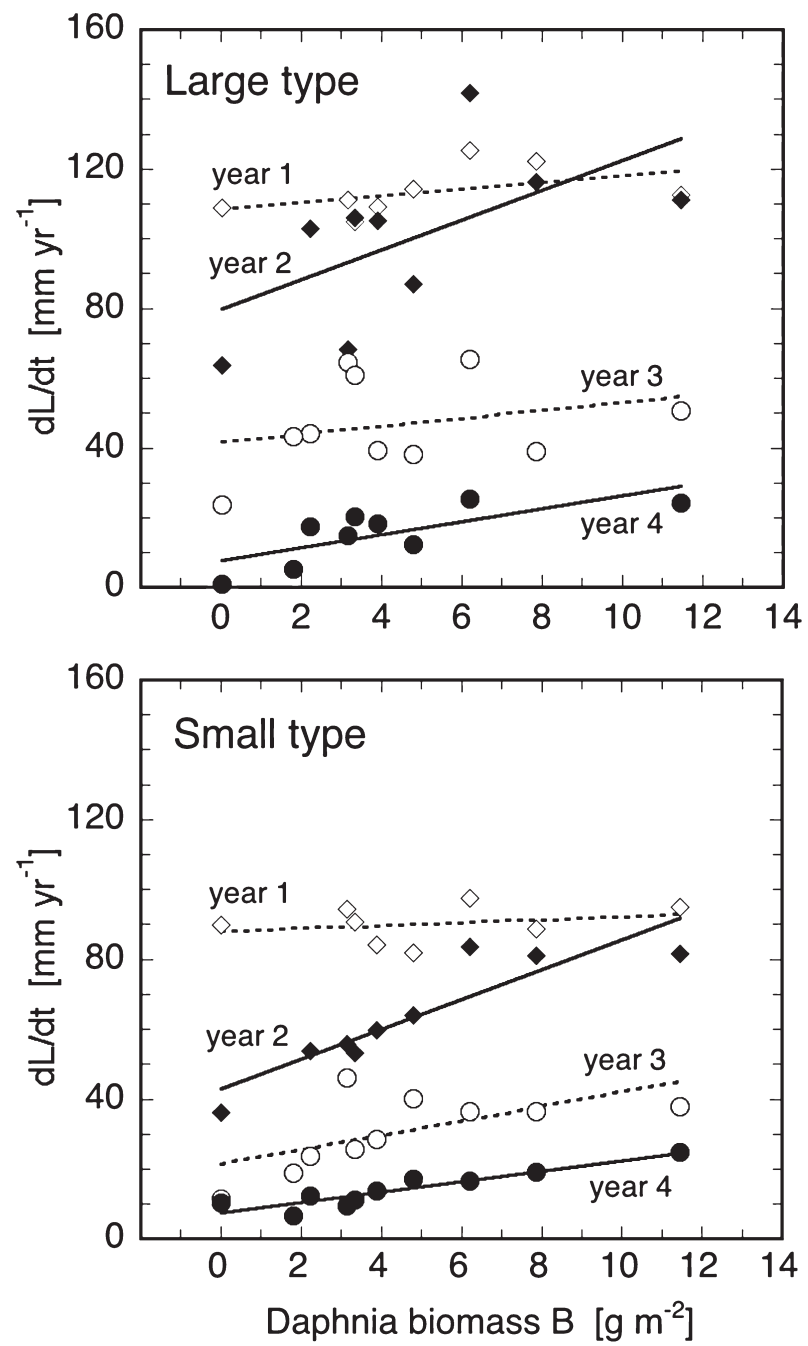

Figure 3. Relationship between mean adult Daphnia biomass B in Lake Brienz, May to September 1995-2004, and mean annual length increase $\mathrm{dL} / \mathrm{dt}$ in large type and small type whitefish, year classes 1993-2002 (from Figure 2). For regression parameters see Table 2.

In parallel with growth, condition slowly decreased during the $1990 \mathrm{~s}$ (Fig. 4). As in growth, condition reached the lowest values in 1999 and 2000. Condition of small type whitefish was significantly lower than that of large type whitefish in years 1990-1996, 19992001 and 2003-2004. In both types, mean condition values in 1999 and 2000 were significantly lower than during the four years before 1999 and after 2000 (twotailed t-tests, $\mathrm{P}<0.01$ ). While condition of large type whitefish after 2000 regained values observed before 1995, condition of small type whitefish did not fully recover after 2000.

Cohort size by number of large type whitefish, as calculated by VPA, varied according to year class but did not exhibit any clear trend (Fig. 5). Conversely, cohort size by number and biomass of small type whitefish strongly decreased, starting already with the cohort in 1984. Combined biomass of both types of coregonids decreased from some 220 tons for cohort 1982 to about 8 tons for cohort 1996 and 11 tons for cohort 1999. It should be noted here that the size of small type cohorts 1997 and later most likely was grossly underestimated because this coregonid could not be caught effectively in the commercial nets due to its small size.

Consumption of daphnids by the whitefish population, as calculated with the bioenergetics model and assuming exclusively adult Daphnia as food organisms, followed the general evolution of trophic state and Daphnia abundance of Lake Brienz (Fig. 6). Maximum consumption was between 2600 and $3800 \mathrm{~kg} \mathrm{~d}^{-1}$ in 1994-1996 but decreased to less than $1000 \mathrm{~kg} \mathrm{~d}^{-1}$ in 1998 and later. The lowest value was found in 1999 when the daphnid population was almost absent. Until 1998 consumption by both types of whitefish showed a similar annual cycle. However, from 1999 on, consumption by small type whitefish apparently did not recover. This is considered an artefact due to the underrepresentation of this whitefish type in the monitoring samples (see above). According to Madenjian et al. (2006), consumption estimates of whitefish, based on physiological parameters of the «generalized coregonid model» (Hanson et al. 1997), might be substantially overestimated. Comparing mean weight of individuals estimated with the bioenergetics model to observed individual mean 


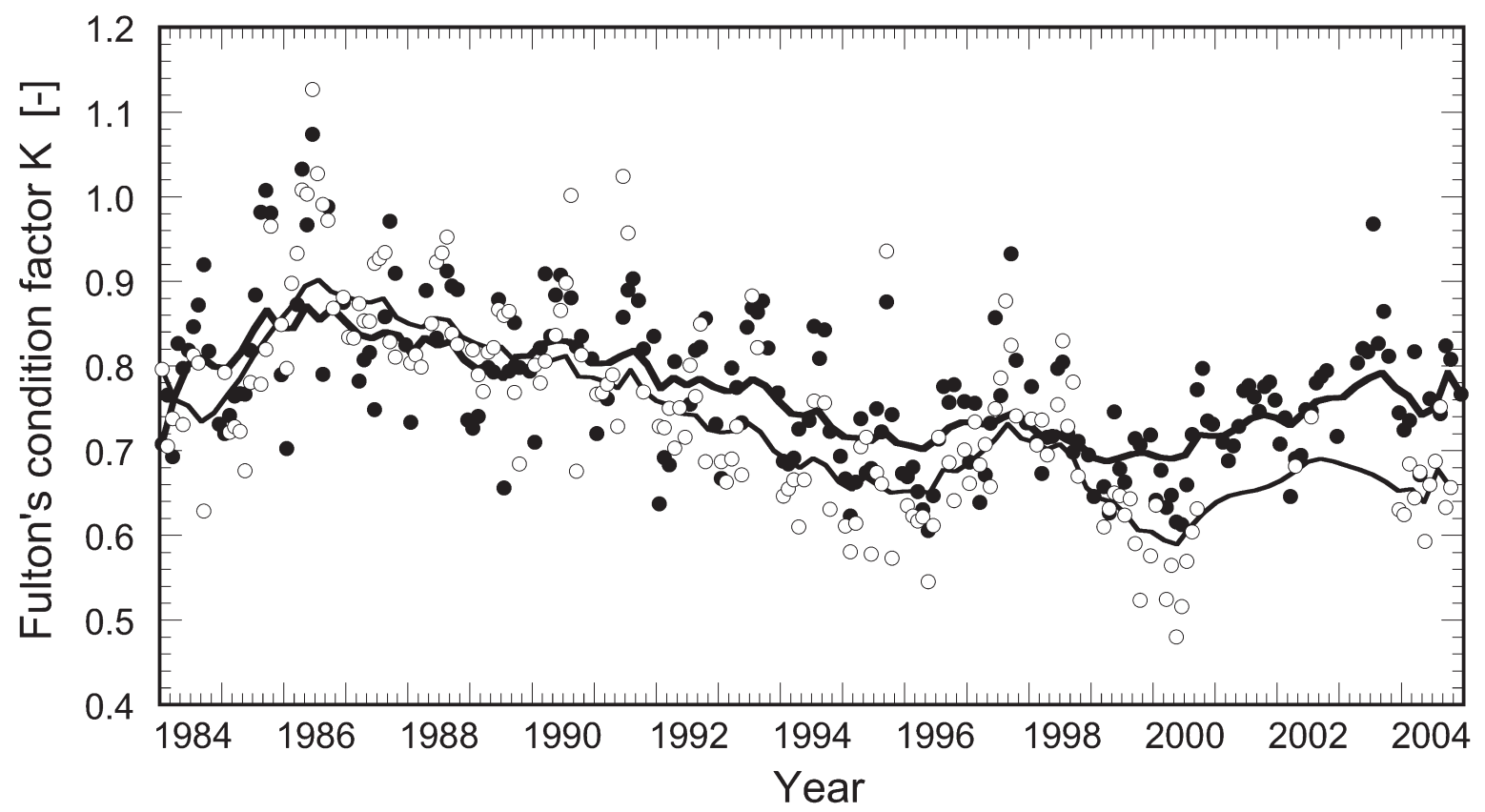

Figure 4. Fulton's condition factor K for large type (dark points, thick line) and small type coregonids (light points, thin line), based on monthly averages for each type. A smooth curve was fitted to these points for each coregonid using locally weighted least-squares (Stineman function in software KaleidaGraph V3.6 by Synergy Software).

weight from monitoring data by month also shows that calculated weight from the bioenergetics model is overestimated for fish below $150 \mathrm{~g}$ and underestimated for larger fish (linear regression with all year classes of large type whitefish and months studied: $\mathrm{W}_{\text {estimated }}=$ $\left.61.451+0.591 \mathrm{~W}_{\text {observed }}, \mathrm{r}^{2}=0.536\right)$. To account for this, consumed daily food rations were reduced by one third in further calculations.

Applying the encounter model to the observed Daphnia densities in the lake, the feeding rate of whitefish varied between $<0.02$ and 0.92 Daphnia s $^{-1}$ in 1994 - 2004, with minimum values far below 0.02 Daphnia s ${ }^{-1}$ in 1999 and 2000. Daily food rations estimated with the bioenergetics model (as numbers of Daphnia $\mathrm{d}^{-1}$ ), combined with the time needed to consume this ration according to the encounter model, at a day length of 8 (November - February), 12 (March - April and September - October) and 16 hours (May - August), reveals that the whitefish did not have enough time to consume their daily ration (Fig. 7). With concentrations at between 30 and 200 adult Daphnia $\mathrm{m}^{-3}$, large type whitefish sometimes ran out of time, and with prey densities below 10 Daphnia $\mathrm{m}^{-3}$, as in 1999-2000, both types of whitefish never had enough time to consume a full daily ration during day time. This «bottom-up effect» explains starvation leading to markedly reduced growth (Fig. 2).

The summed daily Daphnia consumption by whitefish, according to our model estimations (after correction, see above) and observed Daphnia densi- ties, amounted to $0.3-2 \% \mathrm{~d}^{-1}$ of the standing crop of adult Daphnia in the lake in summer, and to 1 to $>10 \% \mathrm{~d}^{-1}$ in winter and spring (Fig. 8). In 1999 and 2000, estimated theoretical Daphnia consumption was between 3 and $>10 \% \mathrm{~d}^{-1}$ of the daphnid population during 17 consecutive months.

Daphnia consumption by the whitefish population is positively correlated with Daphnia standing crop (Fig. 9). Regression analysis with log-log transformed data results in a significant positive slope $(t=5.728$, $p$ $<0.001)$. Therefore it can be concluded that the food chain is «bottom-up»controlled, and that the Daphnia population is not controlled by whitefish foraging (no «top-down effect»).

Detailed stomach analysis of fish caught in 2001 and 2002 (Maurer and Guthruf, 2005) further allowed a seasonally differentiated food regime as input into the bioenergetics model for these two years. This revealed that between January and May insects (mainly chironomid larvae and pupae) contributed to as much as $90 \%$ of the diet of large type whitefish. In spring and early summer, at low Daphnia densities, copepods are consumed as well (Fig. 10). Analysing the influence of whitefish on planktonic populations with this differentiated diet shows that for Daphnia, consumption by whitefish (assuming equal diets for small type and large type) never exceeded $1.5 \% \mathrm{~d}^{-1}$ of total standing crop in 2001-2002. In months with large Daphnia populations, fish consumption was lower than $0.5 \% \mathrm{~d}^{-1}$. For Bythotrephes longimanus, however, daily 

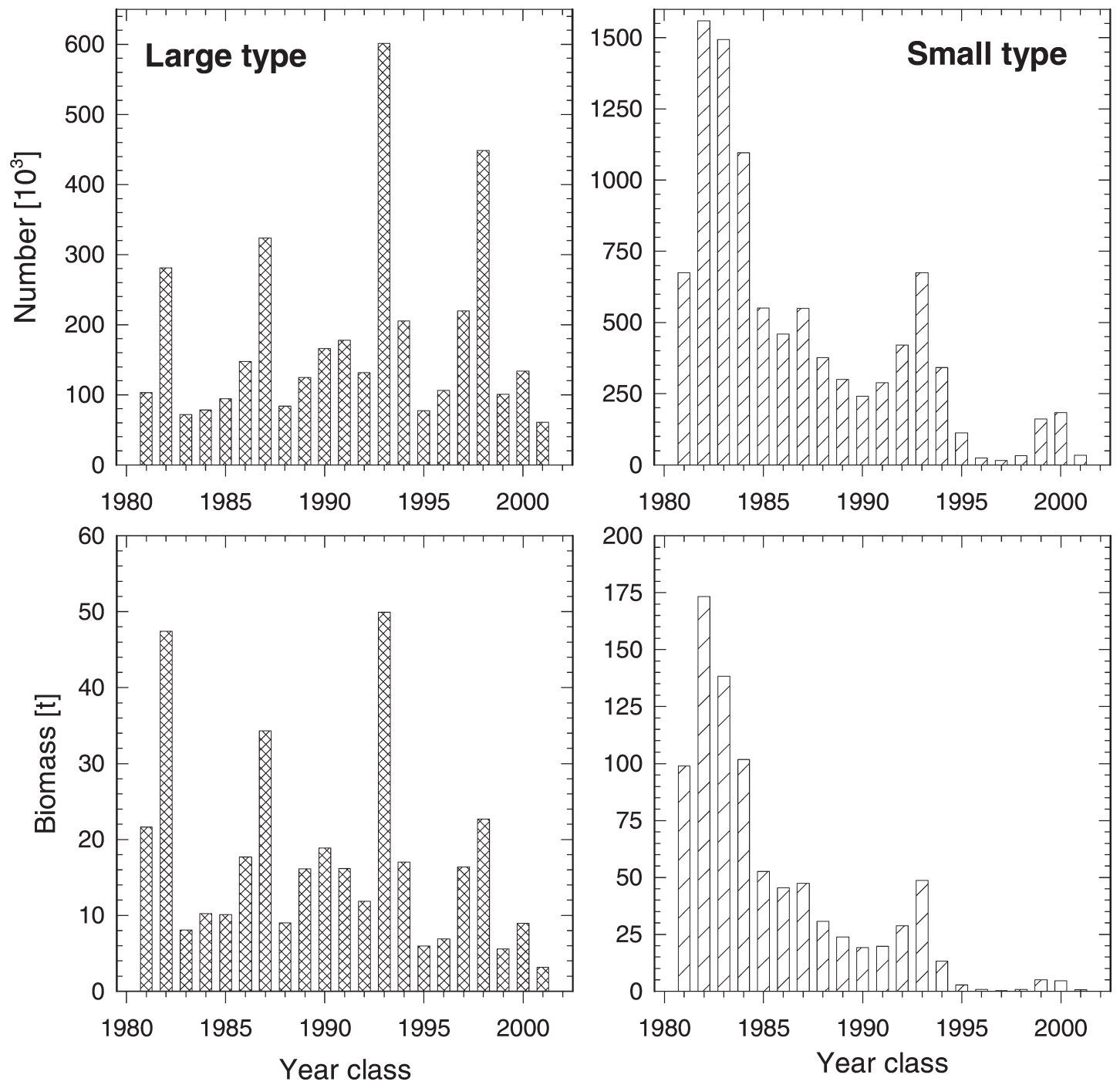

Figure 5. Year class strength (sum of ages 1 to 8 ) by numbers (top) and weight (bottom) of large type (left) and small type (right) whitefish of Lake Brienz, as computed by virtual population analysis. For details see text.

consumption by all whitefish types could amount to as much as $8 \% \mathrm{~d}^{-1}$ of standing crop. For Leptodora kindtii, maximum consumption was $<5 \% \mathrm{~d}^{-1}$.

To study the effect of turbidity on whitefish feeding, two scenarios with extreme light and turbidity conditions in Lake Brienz (data from Jaun et al., 2007) were used to estimate the changes in visual range $R$ and feeding rate $\mathrm{f}$ at a constant food density of 100 Daphnia $\mathrm{m}^{-3}$ at depths from 0 to $80 \mathrm{~m}$ (Fig. 11). At low light and low turbidity conditions as on January $18^{\text {th }}$ 2000 , visual range $\mathrm{R}$ was higher than the feeding range $\mathrm{r}$ down to a depth of $51 \mathrm{~m}$, so that feeding rate $\mathrm{f}$ was at its maximum value of 0.45 Daphnia s ${ }^{-1}$. It was only below this threshold depth that $\mathrm{R}<\mathrm{r}$ and thus feeding rate decreased. On August 12, 2003, with high light and high turbidity conditions due to a layer of suspended solids at $14-33 \mathrm{~m}$ depth, the feeding rate $\mathrm{f}$ was at its maximum down to $13 \mathrm{~m}$ depth, then decreased rapidly. The threshold depth for $\mathrm{R}=\mathrm{r}$ was at $16 \mathrm{~m}$, and at $19 \mathrm{~m}$ depth $\mathrm{f}$ had already decreased to $10 \%$ of its maximum value, inhibiting feeding of whitefish. Between depths of 35 to $42 \mathrm{~m}$, visibility was higher again, which would theoretically allow some feeding activity, if planktonic organisms were present. However, light intensity at this depth did not allow optical foraging by whitefish. Estimating the threshold depth $\mathrm{z}_{\text {critical }}$ with $\mathrm{R}=\mathrm{r}$ as a function of the attenuation coefficient $\mathrm{K}$ with low $\left(\mathrm{E}_{0}=500 \mu \mathrm{E} \mathrm{m}^{-2} \mathrm{~s}^{-1}\right)$ and high $\left(\mathrm{E}_{0}=2500 \mu \mathrm{E} \mathrm{m}^{-2} \mathrm{~s}^{-1}\right)$ light intensities shows that $\mathrm{z}_{\text {critical }}$ is greater than $35-40 \mathrm{~m}$ depth with $\mathrm{K}<0.4 \mathrm{~m}^{-1}$ (= low turbidity), while with $\mathrm{K}>0.8 \mathrm{~m}^{-1}$ (= very high turbidity) $z_{\text {critical }}$ is less than $20 \mathrm{~m}$ depth.

The visual range model was then applied to observed Daphnia densities, turbidity and light inten- 


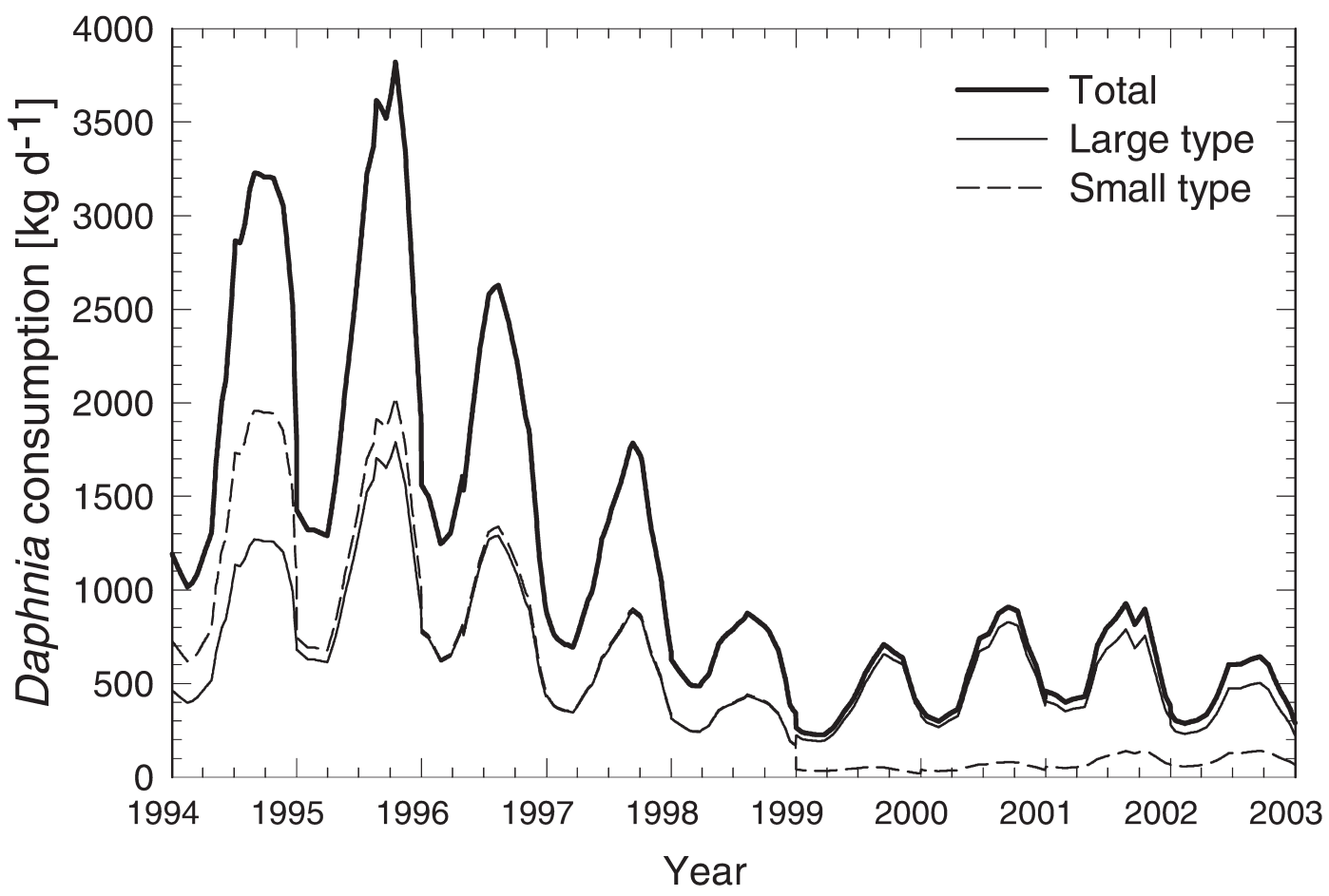

Figure 6. Total consumption of daphnids by small and large type whitefish in Lake Brienz from 1994-2002, based on the bioenergetics model.

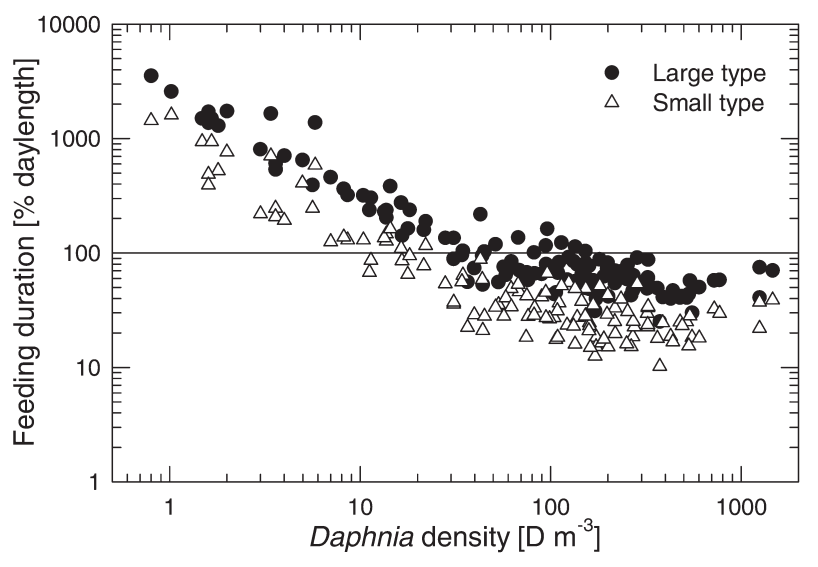

Figure 7. Daphnia density and feeding duration of whitefish (= time to consume one daily ration) related to daylength from 1994 2003 , resulting from the combination of daily consumption rates according to the bioenergetics model and feeding rates according to the encounter model with observed prey densities. The horizontal line indicates $100 \%$, representing day length of 8 (winter), 12 (spring and autumn) or 16 (summer) hours.

sity data as measured in Lake Brienz 1999 - 2004 (Jaun et al., 2007). This shows that mean $\mathrm{K}$ at noon normally was between 0.16 and $0.65 \mathrm{~m}^{-1}$ and only reached higher values of 0.70 in August 2003 and $0.82 \mathrm{~m}^{-1}$ in June 2003. Therefore, $z_{\text {critical }}$ has been far below a depth of $20 \mathrm{~m}$ for most of the time and the feeding rate of whitefish should not have been markedly reduced by insufficient light conditions.
The model then was applied to turbidity and light intensity values resulting from simulations of solids input from dams upstream of the lake (today's situation) and without dams (situation before 1935; Finger et al., 2006). At the euphotic depth $\mathrm{z}_{\mathrm{eu}}$ (seasonally varying between 6 and $28 \mathrm{~m}$ according to measured light data), the feeding rate $\mathrm{f}$ varied between 0.25 Daphnia $\mathrm{s}^{-1}$ in winter and 0.9 Daphnia $\mathrm{s}^{-1}$ in summer and autumn while the threshold depth $z_{\text {critical }}$ was always below $\mathrm{z}_{\mathrm{eu}}$. Today's situation compared to a simulated situation before 1935 shows that without dams, increased concentrations of suspended solids would occur in summer between 10 and $30 \mathrm{~m}$ depth. The increase in turbidity compared with today's situation, however, would not be high enough to change visibility within the upper $35 \mathrm{~m}$. It is only below this depth that feeding rate could be restricted by the increase in turbidity without dams.

\section{Discussion}

Severe growth retardation and poor condition of the whitefish are the obvious cause for the very low yield of the commercial whitefish fishery in Lake Brienz in 1999 and the first half of 2000. Even though the fish were present in the lake, they could not be caught with the legal gillnet mesh sizes because they were too slim. After growth and condition had resumed in 


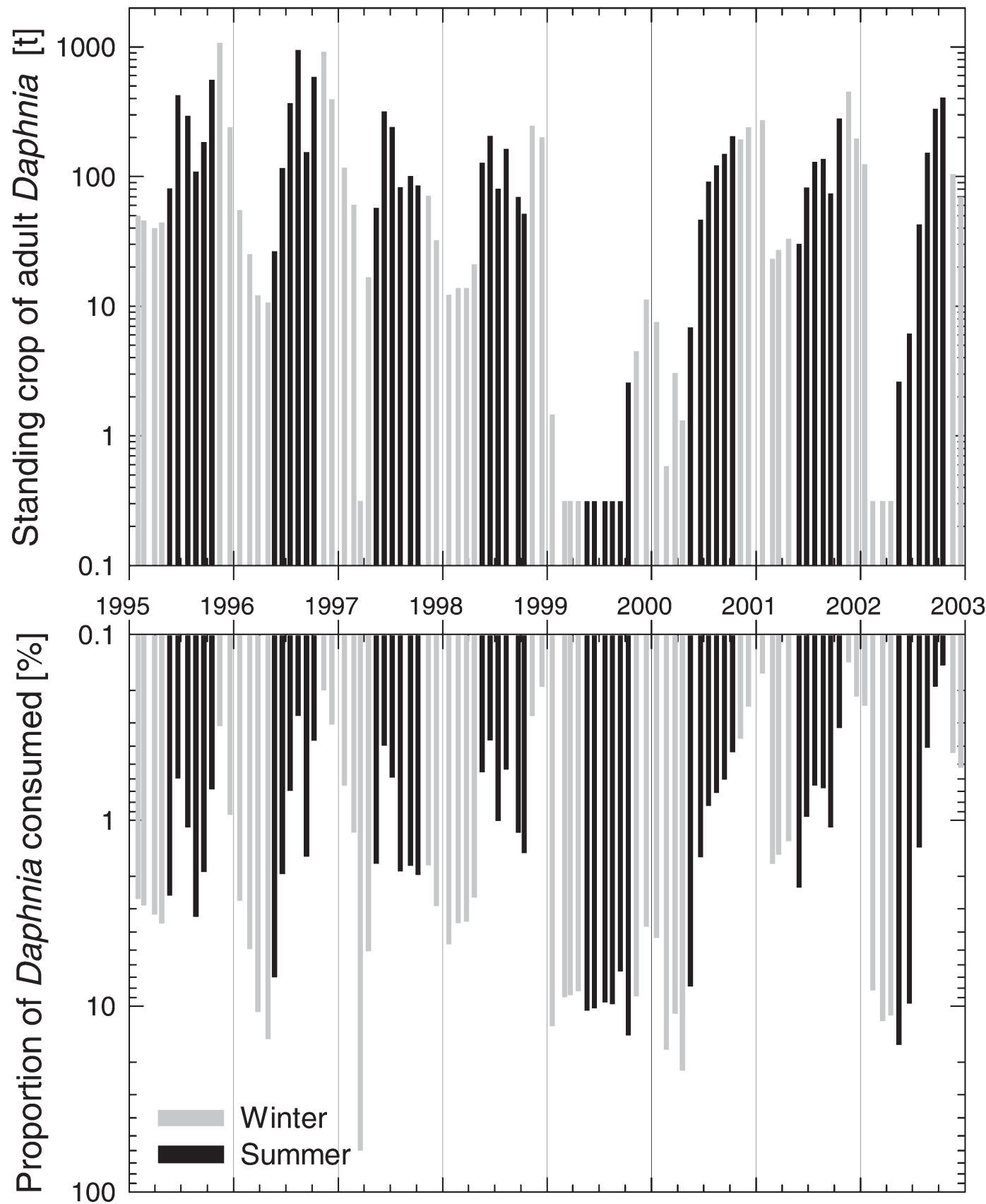

Figure 8. Above: Biomass of adult Daphnia as observed in Lake Brienz (0-100 m depth).

Below: theoretical predation on daphnids by whitefish in percent elimination per day for winter (November-April, light) and summer (May-October, dark), as estimated by the application of the bioenergetics model and the encounter model, assuming exclusively adult Daphnia as food for whitefish.

the second half of 2000, fishing yield started to increase again.

The marked decrease in growth and condition of the Lake Brienz coregonids during 1999 and until June 2000 coincided with the almost complete absence of cladocerans such as Daphnia, Bythotrephes and Leptodora from the plankton community. According to stomach analyses from 2001 and 2002, cladocerans are the main food consumed by coregonids of Lake Brienz
(Maurer and Guthruf, 2005). This is clearly the case for the large type coregonid that made up all but two of the 110 stomach samples analysed. While cladocerans were the dominant food category from March December 2001, benthic chironomid larvae contributed the major part of the food in January, February and April 2002, while copepods were an important food item in March, May and June. Thereafter, cladocerans regained their importance as the domi- 


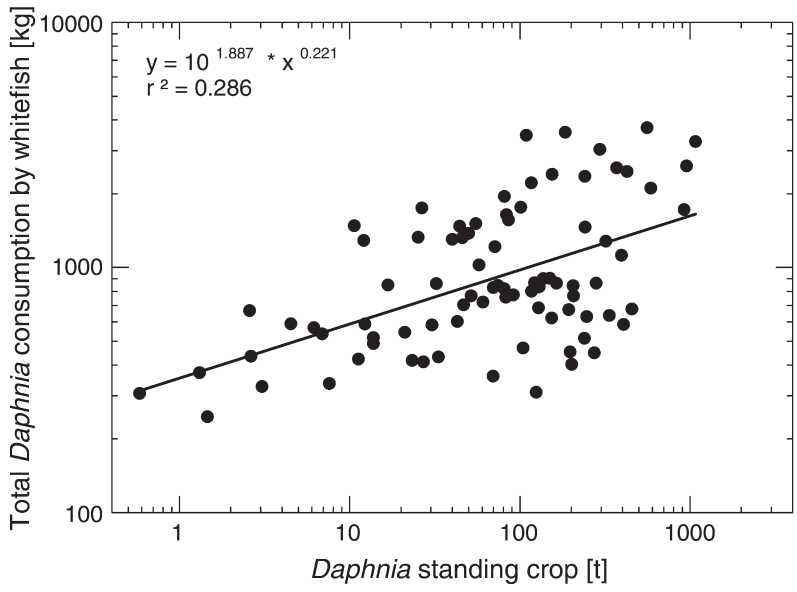

Figure 9. Total estimated Daphnia consumption by all whitefish types (monthly means of daily consumption, January 1995 December 2002) as a function of total Daphnia standing crop (monthly samples of years 1995 - 2002) according to the bioenergetics model. Daphnia densities below detection level (i.e. 43 Daphnia $\mathrm{m}^{-3}$, corresponding to a standing crop of $0.314 \mathrm{t}$ for the whole lake) were omitted.

nant food in summer and autumn. The other two stomach samples, belonging to small type whitefish from April and July 2002, contained almost exclusively Daphnia, Bythotrephes and Leptodora, but no benthic food or copepods. These findings are in agreement with the food preference found for coregonids from other central European lakes, where cladocerans are the dominant food source of sub-adult and adult whitefish during the main growing season (Rufli, 1979; Becker and Eckmann, 1992; Mookerji et al. 1998). The observed relationship between daphnid biomass and growth (Fig. 3) points to a more narrow preference for cladocerans in small type whitefish than in large type whitefish that also feed on benthic food and copepods. Also, the early spawning time of small type whitefish (August - September) may have further impeded their growth because these fish suspend feeding during spawning, and their growth is strongly reduced by the lower daphnid abundance in June-July as was observed after 1998 (Rellstab et al., 2007). In contrast, large type whitefish spawn in December. They could therefore benefit from the daphnid peak that still developed in autumn of 2000 and later. Together with their wider food spectrum in winter and spring, this could explain the observed smaller growth decrease of large type whitefish.

Rellstab et al. (2007) provide evidence that Daphnia abundance in Lake Brienz is mainly controlled by primary production. They conclude that the decrease in the Daphnia population in Lake Brienz in the course of the last 11 years is attributable to decreasing primary production. Our findings also support the existence of a pronounced «bottom-up effect», not only from primary production to zooplankton, but also from zooplankton to planktivorous fish. To our knowledge, this is the first case where zooplankton abundance, and in particular cladoceran density, has been identified as the key factor in the feeding of whitefish and to their growth and condition. Obviously, the very low abundance of Daphnia in 1999 caused the observed growth retardation in both whitefish types, thus making the fish inaccessible to the gillnet fishery. This conclusion is supported by our finding that in these years whitefish simply did not have enough time during the day to consume the number of Daphnia necessary to meet the needs for metabolism and growth (Fig. 7). If considering the uncertainties of the two models at the observed very low Daphnia densities, this result would persist even if the parameters used for the models should slightly change when adapted to Lake Brienz coregonids. The preference of the two whitefishes for cladocerans during the main growing season in summer and fall must be very strong, otherwise the fish would have switched to feeding on copepods that were always abundant in the lake, even in 1999. Further evidence for the «bottom-up control» of whitefish growth and condition is given by our analysis of Daphnia standing crop and consumption, which clearly shows a positive correlation (Fig. 9), indicating that Daphnia density controls whitefish consumption. Thus, hypothesis 1 , stating that low food (zooplankton) concentration, and in particular the very low abundance of daphnids in 1999-2000, was the driving force behind the decline of the whitefish catch is supported.

As was shown by the bioenergetics model applied to the large and small type coregonid stocks in Lake Brienz, the whitefish seemingly eliminated higher proportions of the cladocerans in 1999 than in earlier years. This result was found in spite of the fact that the biomass of whitefish as determined by VPA had decreased substantially between 1990 and 1999 (Fig. 5). Furthermore, our estimates with the bioenergetics model were based solely on consumption of Daphnia, ignoring that large type whitefish - which made up about half of the coregonids in the 1998 and 1999 catch (Table 1) - also feed on benthic food and on copepods at some time of the year (Fig. 10). At the end of 1998, the density of Daphnia in the lake representing the start-up population for 1999 was at about the same level as at the end of 1997 (Rellstab et al., 2007). However, contrary to1998, the Daphnia population did not reach detectable levels in 1999. It should be kept in mind that applying the parameters of the "generalized coregonid model" (Rudstam et al., 1994; cited in Hanson et al., 1997) elaborated for North American whitefish to alpine whitefish species for bioenergetic modelling introduces considerable un- 

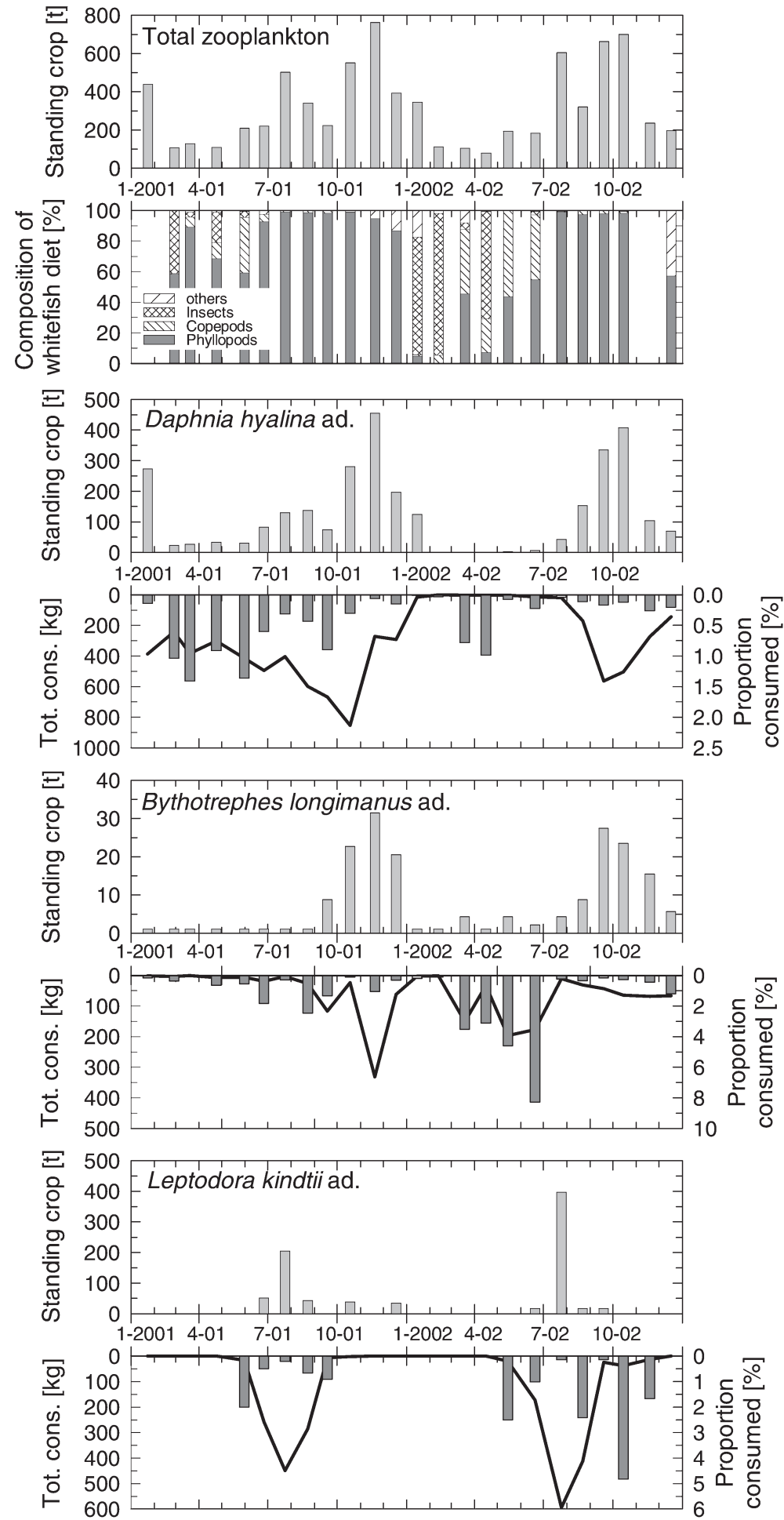

Figure 10. Biomass of total zooplankton in Lake Brienz and diet composition according to stomach samples of large type whitefish in 2001 - 2002 (top two panels). Standing crop of three main diet zooplankton species (upper bars), total consumption by large type whitefish (lines with left axis), and proportion of prey biomass consumed (lower bars with right axis).

certainty. As pointed out by Madenjian et al. (2006), consumption by whitefish is overestimated when using these model parameters. To account for this we reduced consumption by one third. Without this reduction, estimated predation rates of whitefish on Daphnia would have been higher (0.56 - 4.97\% instead of $0.38-3.31 \%$ ) in summers of $1995-1997$, but still without any detectable effect on the Daphnia 


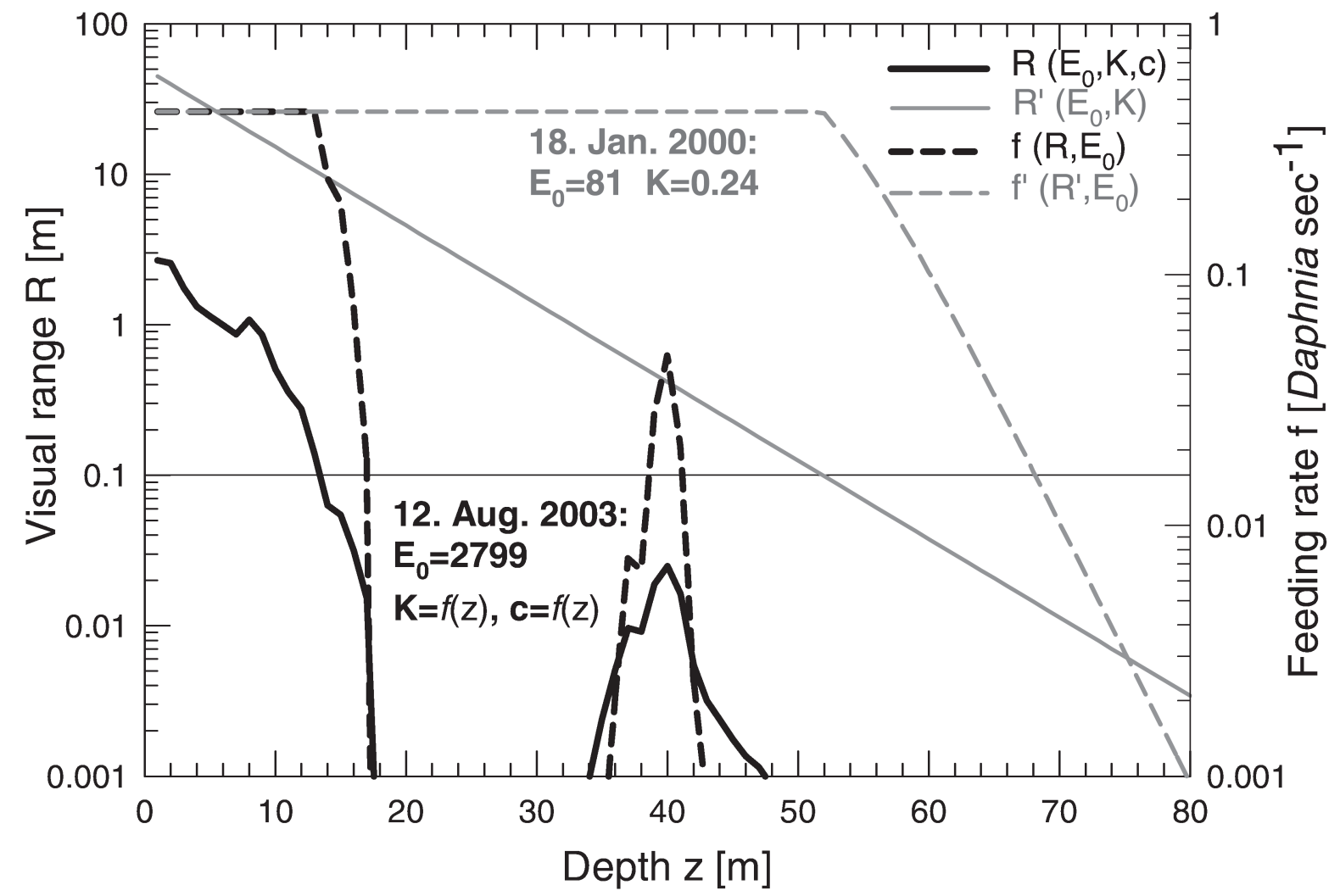

Figure 11. Influence of light intensity and turbidity on visual range R (solid line with left axis) and feeding rate f of whitefish (broken line with right axis) as a function of radiation $\left(\mathrm{E}_{0}\right)$, attenuation $(\mathrm{K}, \mathrm{c})$ and depth $(\mathrm{z})$ on two days with different light conditions in Lake Brienz. At depth where visual range $R$ equals activity radius $r=0.1 \mathrm{~m}$, the feeding rate begins to decline markedly.

population in the following springs. We therefore conclude that in 1999 the Lake Brienz coregonids did not exert such an increased predation pressure as to eliminate almost all Daphnia from the lake in a season when phyllopod consumption is at its lowest. Also, during periods of much higher fish biomass in 1995 and 1996, the whitefish never consumed cladocerans so much to make them disappear from plankton samples. We cannot fully exclude that the whitefish in 1999 did not further decimate the already scant Daphnia population. Still, the higher Daphnia consumption in former and later years does not allow the conclusion that the disappearance of daphnids in 1999 was mainly caused by whitefish predation. This argument is supported by the findings of Rellstab et al. (2007) who conclude that the very low Daphnia population in 1999 was primarily the result of low spring water temperature and the extraordinary spring flood in 1999 resulting in a "flushing out effect" of cladocerans. High predation rates on cladocerans always occurred when prey populations were near or even below the detection limit, which introduces further uncertainty into the estimation of predation. However, our results of predation pressure on Daphnia, Bythotrephes and Leptodora by whitefish corre- spond quite well with model results for Lake Constance zooplankton and whitefish populations (Eckmann et al., 2002). Furthermore, the analysis of the relation between daphnids and whitefish consumption (Fig. 9) clearly indicates a bottom-up control, thus excluding top-down control of foragers over their food organisms. Therefore, hypothesis 2 stating that the daphnid stocks were significantly influenced by whitefish predation between 1995 and 2003 («top-down effect») is rejected.

The encounter and feeding rate models, coupled with information on the effect of reduced visibility on the feeding of fish, did not provide any conclusive evidence that the turbidity occurring in Lake Brienz could have hampered the feeding of whitefish in 1999-2000. The highest turbidity was usually detected at a depth below $10 \mathrm{~m}$ (Finger et al., 2006), while the whitefish apparently fed at lesser depths because they were always caught at about $10 \mathrm{~m}$ depth or less during the main growing season in summer and autumn (Fisheries Agency of the Canton Bern, unpublished data). Turbidity in 1999 lasted longer but was neither more intensive nor higher up in the depth range of the feeding whitefish than in other years (Finger et al., 2006). Our model estimates show that the feeding rate 


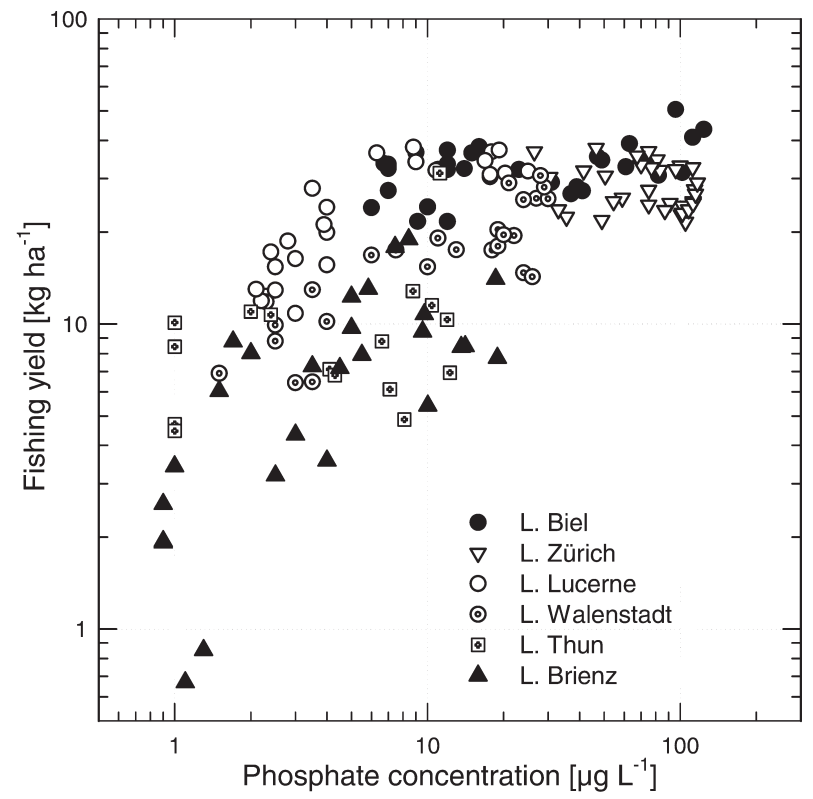

Figure 12. Annual commercial fishing yield, all fish species, in relation to phosphate (soluble reactive phosphorus) concentration during spring circulation in six Swiss lakes with important whitefish stocks.

may be influenced by turbidity below the euphotic depth. However, as minimum light intensity for feeding activity of planktivorous fish (Koski and Johnson, 2002) at noon was at a depth of $9-15 \mathrm{~m}$ in summer and at $25-30 \mathrm{~m}$ in winter, this does not seem relevant to whitefish in Lake Brienz. Rather, it appears that the density of daphnids and other cladocerans was low already in the beginning of 1999 until June 2000. Hypothesis 3, assuming that elevated turbidity had a strong negative effect on the feeding of the whitefish in 1999 and 2000 is therefore rejected.

\section{Conclusions}

Lake Brienz in its present state is a deep, cold and oligotrophic pre-alpine lake with very low primary production. This state is the intended result of the water protection measures taken in fulfilment of the Swiss environmental legislation. Fishing yield is at the end of the production chain and is more or less closely related to primary production. Generally, mesotrophic and moderately eutrophic lakes show high productivity and support high fishing yield, while oligotrophic waters are characterised by low primary production and low fishing yield. It is therefore not surprising that the fishery in Lake Brienz has seen its demise after a number of years with high yields during the mesotrophic period. Our data suggest that this evolution is primarily the result of the changing nutrient concentration in the lake.

The situation of the Lake Brienz fishery today can be highlighted by comparing its fishing yield and soluble phosphorus (SRP) concentration with that in some other Swiss lakes (Fig. 12). Lake Brienz is clearly situated at the lower end of both phosphorus concentration and yield. Therefore, at a phosphorus concentration around or slightly below $1 \mu \mathrm{g} \mathrm{L}^{-1}$, fishing yield in Lake Brienz can be expected to be in the order of about $1-3 \mathrm{~kg} \mathrm{ha}^{-1}$ at best. This includes the yield from the intensified exploitation of the abundant small type whitefish with $20 \mathrm{~mm}$ nets legalised in the beginning of 2006.

Comparing the estimated carrying capacity of Lake Brienz with the actual whitefish population as estimated by VPA reveals that the carrying capacity markedly declined from 1995 to 2002 (Fig. 13). During summer and autumn months the whitefish stock was smaller than could be supported by the lake's Daphnia production before 1999 and after 2000. However, from January 1999 to May 2000, the whitefish stock clearly exceeded the extraordinarily low carrying capacity as is shown by both models. This finding confirms the above conclusion that the fish were starving in 1999 and 2000. It further supports the above thesis that fishing yield will stay low as long as nutrient concentration and thus the production of whitefish food remain at the present low level. The option of moderately increasing nutrient concentrations by adding phosphorus in a controlled way and thus increasing primary and secondary production and fishing yield (Mills and Chalanchuk, 1988; Mills et al., 1998) is not feasible under the present legal regulations.

Food chains in such oligotrophic systems are fragile, as it has been demonstrated by the 1999 event. Our data document the first case where whitefish populations in ultra-oligotrophic lakes are governed by «bottom-up» control. It is therefore likely that poor cladoceran development and poor growth of whitefish in this system will happen again in the future. Such events are basically beyond human control and go along with ultra-oligotrophic lacustrine systems.

\section{Acknowledgments}

The present study is part of a collaborative research project on ecological changes in Lake Brienz. The study was funded by the Government of the Canton Bern, Kraftwerke Oberhasli AG (KWO), the Swiss Federal Office for the Environment (FOEN), the communities on the shores of Lake Brienz, and Eawag. The authors would like to thank the colleagues 

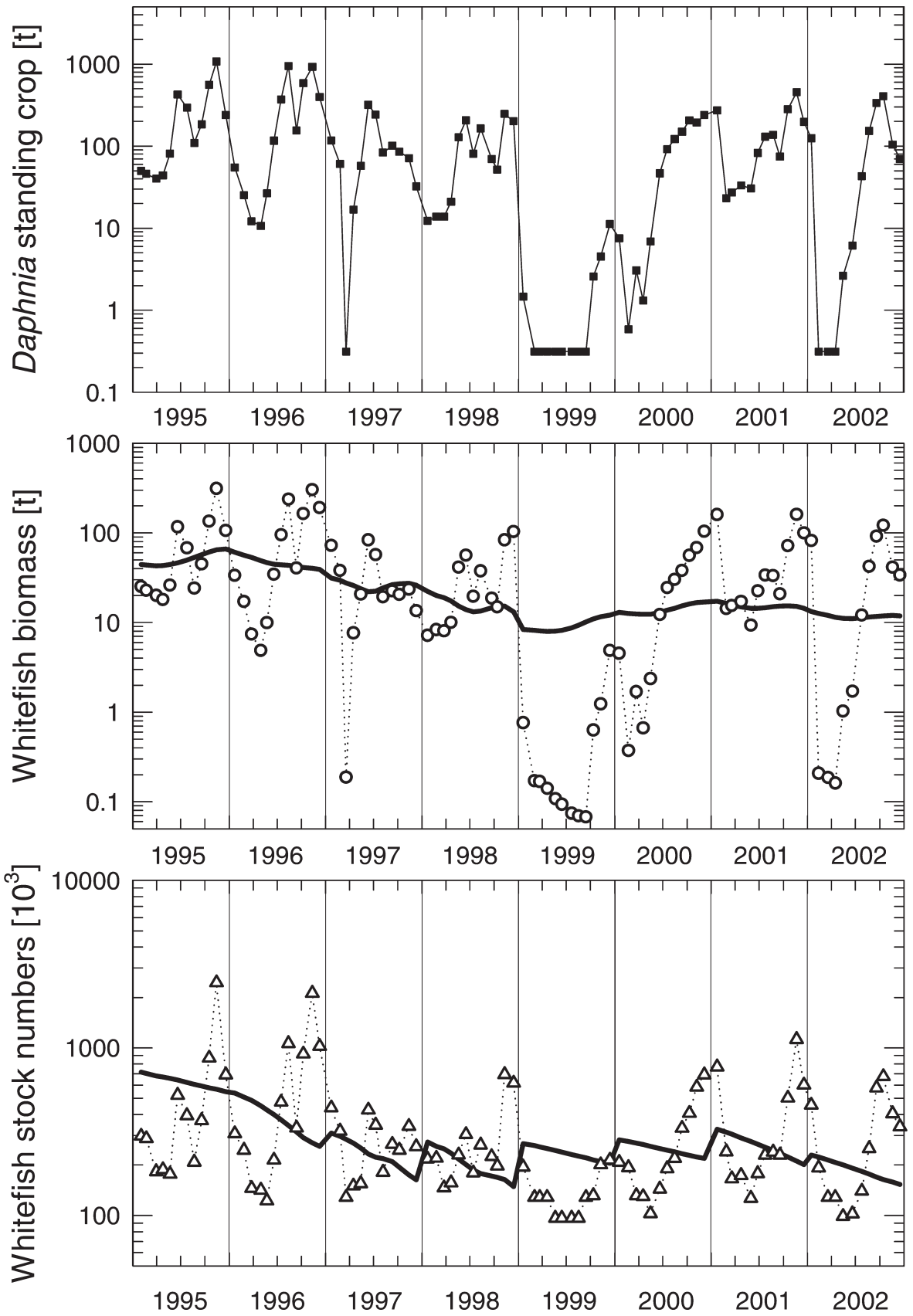

Figure 13. Total Daphnia biomass (upper panel), whitefish stock biomass according to VPA (solid line, middle panel) and carrying capacity estimated with the bioenergetics model based on Daphnia biomass (open circles, middle panel), whitefish stock in numbers according to VPA (solid line, lower panel) and carrying capacity estimated with the encounter model based on Daphnia numbers (open triangles, lower panel).

of the working group for fruitful discussions. The Fisheries Agency of the Canton Bern kindly provided data and scale samples of whitefish. The constructive comments by O. Seehausen and three anonymous referees are greatly acknowledged.

\section{References}

Aksnes, D. I. and J. Giske, 1993. A theoretical model of aquatic visual feeding. Ecological Modelling 67: $233-250$.

Aksnes, D. I. and A. C. W. Utne, 1997. A revised model of visual range in fish. Sarsia 82: $137-147$.

Becker, M. and R. Eckmann, 1992. Plankton selection by pelagic European whitefish in Lake Constance: dependency on season and time of day. Polskie Archiwum Hydrobiologii 39: 393 402.

Bernatchez, L. and J. J. Dodson 1994. Phylogenetic relationships 
among palearctic and nearctic whitefish (Coregonus sp.) populations as revealed by mitochondrial DNA variation. Canadian Journal of Fisheries and Aquat. Sci. 51 (Suppl. 1): $240-251$.

Büttiker, B., 1975. Untersuchung über die Körperform, Bewegung und Schwimmleistung einiger einheimischer Fischarten. Dissertation, Universität Bern, 97 pp.

Douglas, M., 1998. Central alpine Coregonus (Teleostei, Coregonidae): Evolution and conservation of a unique assemblage. Dissertation, Universität Zürich, 203 pp.

Downing, J. A., and C. Plante, 1993. Production of fish populations in lakes. Canadian Journal of Fisheries and Aquat. Sci. 50:110120 .

Downing, J.A., C. Plante and S. Lalonde, 1990. Fish production correlated with primary productivity, not the morphoedaphic index. Canadian Journal of Fisheries and Aquat. Sci. 47: 19291936.

Eckmann, R., M. Becker and M. Schmid, 2002. Estimating food consumption by a heavily fished stock of zooplanktivorous whitefish. Transactions of the American Fisheries Society 131: 946-955.

Eckmann, R. and R. Rösch, 1998. Lake Constance fisheries and fish ecology. Archiv für Hydrobiologie - Advances in Limnology 53: $285-301$.

Finger, D., P. Bossard, M. Schmid, L. Jaun, B. Müller, D. Steiner, E. Schäffer, M. Zeh and A. Wüest, 2007. Effects of alpine hydropower operations on primary production in a downstream lake. Aquat. Sci. 69: doi 10.1007/s00027-007-0873-6.

Finger, D., M. Schmid, and A. Wüest, 2006. Effects of upstream hydropower operation on riverine particle transport and turbidity in downstream lakes. Water Resources Research 42, W08429, doi:10.1029/2005WR004751.

Gaedke, U., 1999. The response of the pelagic food web to reoligotrophication of a large and deep lake (L. Constance): Evidence for scale-dependent hierarchical patterns? In Bäuerle, E. and U. Gaedke (eds.) Lake Constance. Characterization of an ecosystem in transition, Archiv für Hydrobiologie - Advances in Limnology 53: 317 - 333.

Gerking, S.D. (ed.), 1978. Ecology of Freshwater Fish Production. Blackwell Scientific Publications, 520 pp.

Haddon, M., 2001. Modelling and quantitative methods in fisheries. Chapman \& Hall, 406 pp.

Hanson, P. C., T. B. Johnson, D. E. Schindler and J. E. Kitchell, 1997. Fish bioenergetics 3.0. University of Wisconsin, Sea Grant Institute, Center for Limnology, Madison.

Jaun, L., D. Finger, M. Zeh, M. Schurter and A. Wüest, 2007. Effects of upstream hydropower operation and oligotrophication on the light regime of a turbid peri-alpine lake. Aquat. Sci. 69: doi 10.1007/s00027-007-0876-3.

Jeppesen, E., M. Søndergaard, J. P. Jensen, K. Havens, O. Anneville, L. Carvalho, M. F. Coveney, R. Deneke, M. Dokulil, B. Foy, D. Gerdeaux, S. E. Hampton, K. Kangur, J. Köhler, S. Körner, E. Lammens, T. L. Lauridsen, M. Manca, R. Miracle, B. Moss, P. Nõges, G. Persson, G. Phillips, R. Portielje, S. Romo, C. L. Schelske, D. Straile, I. Tatrai, E. Willén and M. Winder, 2005. Lake responses to reduced nutrient loading - an analysis of contemporary data from 35 European and North American long term studies. Freshwater Biology 50: 1747 - 1771.

Jobling, M., 1995. Environmental biology of fishes. Chapman and Hall, Fish and Fisheries Series 16: 1 - 455.

Kaiser, M. S., P. L. Speckman and J. R. Jones, 1994. Spatial models for limiting nutrient relations in inland waters. Journal of the American Statistical Association 89: 410 - 423.

Kirchhofer, A., 1990: Limnologische und ichthyologische Untersuchungen im Brienzersee unter besonderer Berücksichtigung der Differenzierung der sympatrischen Felchenpopulationen. Dissertation, Universität Bern, 102 pp. http://www.eawag.ch/ brienzersee.

Kirchhofer, A., 1995. Growth characteristics of coregonid populations in three lakes with different trophic states and decreasing nutrient concentrations. Archiv für Hydrobiologie - Advances in Limnology 46: 61 - 70.
Kirchhofer, A., M. Breitenstein, M. Flück and C. Küng, 2005: Die Felchenfänge der Berufsfischer von Brienzersee, Thunersee und Bielersee 1984 - 2005. Mitteilungen zur Fischerei 80: 15 37, Bundesamt für Umwelt, Wald und Landschaft. Bern.

Koski, M. L. and B. M. Johnson, 2002. Functional response of kokanee salmon (Oncorhynchus nerka) to Daphnia at different light levels. Canadian Journal of Fisheries and Aquat. Sci. 59: $707-716$.

Kottelat, M., 1997. European freshwater fishes. An heuristic checklist of the freshwater fishes of Europe (exclusive of former USSR), with an introduction for non-systematists and comments on nomenclature and conservation. Biologia, Bratislava 52 (Supplement 5): 1 - 271.

Liechti, U., 1994. Der Zustand der Seen in der Schweiz. Schriftenreihe Umwelt 237. Bundesamt für Umwelt, Wald und Landschaft, Bern, 159 pp.

Link, J., 1996. Capture probabilities of Lake Superior zooplankton by an obligate planktivorous fish - the lake herring. Transactions of the American Fisheries Society 125: $139-142$.

Link, J., 1998. Dynamics of lake herring (Coregonus artedi) reactive volume for different crustacean zooplankton. Hydrobiologia 368: $101-110$.

Madenjian, C. P., D. V. O‘Connor, S. A. Pothoven, P. J. Schneeberger, R. R. Rediske, J. P. O'Keefe, R. A. Bergstedt, R. L. Argyle and S. B. Brandt, 2006. Evaluation of a lake whitefish bioenergetics model. Transactions of the American Fisheries Society 135: $61-75$.

Maurer, V. und K. Guthruf, 2005. Brienzerseefelchen - Mageninhaltsanalysen, Schlussbericht Routineprogramm. Bericht an das Fischereiinspektorat des Kantons Bern, HYDRA, 18 pp. http://www.eawag.ch/brienzersee .

Megrey B.A., 1989. Review and comparison of age-structured stock assessment models from theoretical and applied points of view. In E.F. Edwards and B.A. Megrey (eds.). Mathematical analysis of fish stock dynamics. American Fisheries Society Symposium 6: $8-48$.

Mills, K. H. and S. M. Chalanchuk, 1988. Population dynamics of unexploited Lake Whitefish (Coregonus clupeaformis) in one experimentally fertilized lake and three unexploited lakes. Finnish Fisheries Research 9: 145 - 153.

Mills, K. H., B. R. McCulloch, S. M. Chalanchuk, D. J. Allan and M. P. Stainton, 1998. Growth, size, structure, and annual survival of Lake Whitefish (Coregonus clupeaformis) during the eutrophication and oligotrophication of Lake 226, the Experimental Lakes Area, Canada. Archiv für Hydrobiologie Advances in Limnology 50: 151 - 160.

Mittelbach, G. G., 1981. Foraging efficiency and body size: a study of optimal diet and habitat use by bluegills. Ecology 62: $1370-$ 1386.

Mookerji, N., C. Heller, H. J. Meng, H. R. Bürgi and R. Müller, 1998. Diel and seasonal patterns of food intake and prey selection by Coregonus sp. in re-oligotrophicated Lake Lucerne, Switzerland. Journal of Fish Biology 52: 443 - 457.

Müller, B., D. Finger, M. Sturm, V. Prasuhn, T. Haltmeier, P. Bossard, C. Hoyle, and A. Wüest, 2007. Present and past bioavailable phosphorus budget in the ultra-oligotrophic Lake Brienz. Aquat. Sci. 69: doi 10.1007/s00027-007-0871-8.

Müller, R., 2003. Populationsdynamische Untersuchungen an den Felchen des Brienzersees. Bericht an das Fischereiinspektorat des Kantons Bern. EAWAG Kastanienbaum, 81 pp. http:// www.eawag.ch/brienzersee.

Müller, R. and M. Mbwenemo Bia, 1998. Adaptive management of whitefish stocks in lakes undergoing re-oligotrophication: The Lake Lucerne example. Archiv für Hydrobiologie - Advances in Limnology 50: 391 - 399 .

Müller, R. and P. Stadelmann, 2004. Fish habitat requirements as the basis for rehabilitation of eutrophic lakes by oxygenation. Fisheries Management and Ecology 11: 251 - 260.

Rellstab, C., V. Maurer, M. Zeh, H. R. Bürgi and P. Spaak, 2007. Temporary collapse of the Daphnia population in turbid and ultra-oligotrophic Lake Brienz. Aquat. Sci. 69: doi 10.1007/ s00027-007-0872-7. 
Rellstab, C., H. R. Bürgi and R. Müller, 2004. Population regulation in coregonids: the significance of zooplankton concentration for larval mortality. Annales Zoologici Fennici 41: $281-290$

Ricker, W. E., 1975. Computation and interpretation of biological statistics of fish populations. Bulletin of the Fisheries Research Board of Canada 191: 1 - 382 .

Rudstam, L. G, F. P. Binkowski and M. A. Miller, 1994. A Bioenergetics model for analysis of food consumption patterns of Bloater in Lake Michigan. Transactions of the American Fisheries Society 123: $344-357$.

Rufli, H., 1979. Ernährung und Wachstum der Felchenpopulatio- nen (Coregonus spp.) des Thuner- und Bielersees. Schweizerische Zeitschrift für Hydrologie 41: 64 - 93.

Stich, H. B., M. Pfeiffer and G. Maier, 2005. Zooplankton communities in a large prealpine lake, Lake Constance: comparison between the Upper and the Lower Lake. Journal of Limnology 64: 129 - 138 .

Vinyard, G. L. and W. J. O'Brien, 1976. Effects of light and turbidity on the reactive distance of bluegill (Lepomis macrochirus). Journal of the Fisheries Research Board of Canada 33: 2845 2849.

Wüest, A., M. Zeh and J. D. Ackermann, 2007. Lake Brienz Project: An interdisciplinary catchment-to-lake study. Aquat. Sci. 69: doi 10.1007/s00027-007-0016-0.

\section{To access this journal online: http://www.birkhauser.ch/AS}

